\title{
Deformation of aluminum alloys AD-1, AMg-6 and D-16 at dynamic compression and temperatures of 25250 C
}

\author{
V. A. Pushkov, S. A. Novikov, V. A. Sinitsyn, \\ I. N. Govorunov \& O. N. Ignatova \\ Russian Federal Nuclear Center - VNIIEF, Russia
}

\begin{abstract}
Using the Kol'sky method, the authors studied dynamic diagrams of uniaxial compression of aluminum alloys $\mathrm{AD}-1, \mathrm{AMg}-6$, and $\mathrm{D}-16$. These alloys are applied in aviation, space technologies, shipbuilding and many other industries. Alloys similar to the above mentioned alloys have been studied abroad as well (for example, aluminum alloys 1100-0, 5182, 6061-T6); however in general data on dynamic deformation of the mentioned aluminum alloys have been obtained only at normal temperature. In this work, we performed systematized research of the aluminum alloys at strain rates of $200-1400 \mathrm{~s}^{-1}$ and temperatures of 25 $250^{\circ} \mathrm{C}$.

Keywords: Kol'sky method, compression, temperature, strain rates, aluminum alloys, temperature and velocity dependencies $\sigma_{-0.2}$, model of strength.
\end{abstract}

\section{Introduction}

Study of dynamic mechanical properties of structural materials is an urgent problem for many areas of science and engineering, and VNIIEF experts are actively involved into efforts for solving this problem. The Kol'sky method [1] is one of the reliable methods for study of dynamic mechanical properties of materials at strain rates of $10^{2}-10^{4} \mathrm{~s}^{-1}$. In its classical form, it is intended to study dynamic diagrams of uniaxial compression $\sigma-\varepsilon$. The method falls into the category of tests with the parameter $\dot{\varepsilon}=\mathrm{d} \varepsilon / \mathrm{d} t=$ const, i.e. with constant strain rate. The method essence is quasistatic loading of a sample placed between two steel bars by passing and reflected waves of stresses. The bars are in elastic state, while the sample undergoes elastic-plastic deformation. Various techniques of 
dynamic tests are presently based on the Kol'sky method principles. These techniques are used in tests with extension, torsion, torsion simultaneously with compression or extension, crack-resistance tests, tests for study of the Baushinger's effect $[2,3]$.

\section{Research results}

Using the Kol'sky method, the authors studied dynamic diagrams of uniaxial compression of aluminum alloys AD-1, AMg-6, and D-16. These alloys are applied in aviation, space technologies, shipbuilding, and many other industries. Available data on these alloys are mostly data obtained at static velocities of loading [4]. There are some data obtained under dynamic loading, but only for normal temperature [5-8]. Alloys similar to the above mentioned alloys have been studied abroad as well (for example, aluminum alloys 1100-0, 5182, 6061T6), strain diagrams have been obtained for them as well, but they are also for normal temperature [9-11]. In this work, we performed systematized researches of the aluminum alloys at strain rates of $200-1400 \mathrm{~s}^{-1}$ and temperatures of $25-250^{\circ} \mathrm{C}$. Samples in as-delivered condition having sizes $\varnothing 8 \times 8 \mathrm{~mm}$ were studied. In each experiment, diagrams of dynamic compression were obtained, and yield strengths $\sigma_{-0.2}$ were determined. The diagrams were plotted in the "stress intensity - strain intensity" coordinates. Recalculation was performed using the dependencies taking account for change of the effective Poisson's ratio in the area of elastic-plastic transition, eqns (1) and (2):

$$
\begin{gathered}
\sigma_{\mathrm{i}}=\sigma /\left[1-\mu^{\prime} \cdot \ln (1+\varepsilon)\right]^{2} \\
\varepsilon_{\mathrm{i}}=2 \cdot\left(1+\mu^{\prime}\right) \cdot \ln (1+\varepsilon) / 3
\end{gathered}
$$

In eqns (1) and (2) $\mu^{\prime}=0.5-0.5 \cdot \sigma \cdot(1-2 \cdot \mu) /(\mathrm{E} \cdot \varepsilon)$. Fig 1 shows averaged diagrams $\sigma_{\mathrm{i}}{ }^{-}$ $\varepsilon_{\mathrm{i}}$ of the alloys. To make the figure simpler, the diagrams are given for each material at temperatures of 25 and $250^{\circ} \mathrm{C}$ (the diagrams at $150^{\circ} \mathrm{C}$ are located in the middle). Experiments revealed that strain hardenings of alloys D-16 and AMg-6 were approximately the same, and it was higher than that of alloy AD- 1 . D-16 is the hardest, and AMg-6 and AD-1 are located in the decreasing order (see Fig 1).

The yield strengths temperature dependencies $\sigma_{-0.2}=\mathrm{f}(T)$ and velocity dependencies $\sigma_{-0.2}=f(\dot{\varepsilon})$ are shown in Fig 2 and Fig 3. The same as in Fig 1, the dependencies in Fig 3 are given at temperatures of 25 and $250^{\circ} \mathrm{C}$. These dependencies have generally the linear character. It should be noted that the velocity dependence $\sigma_{-0.2}$ does not evidently result from curves 7, 8 (for AMg-6) and curves 11, 12 (for AD-1) from Fig 1. However, in Fig 3, where results of each experiment are pointed, one can see, nevertheless, the weak dependence of $\sigma_{-0.2}$ on $\dot{\varepsilon}$ for the mentioned materials. It follows from Fig 2 and Fig 3 that the strongest change of $\sigma_{-0.2}$ occurs in D-16 with growth of $T$ and $\dot{\varepsilon}$, and the weakest change occurs in AD-1. 


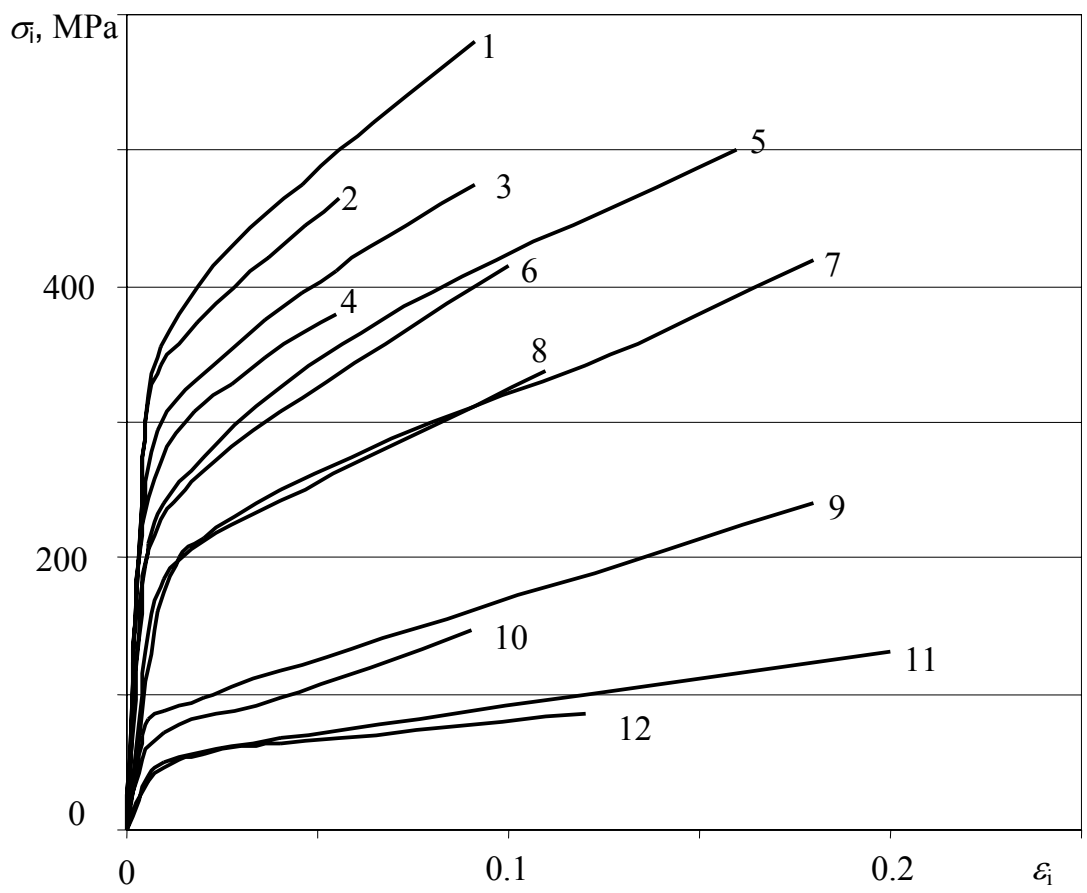

Figure 1: Averaged diagrams of dynamic compression of aluminum alloys. D-16: $\quad 1-T=25^{\circ} \mathrm{C}, \quad \dot{\varepsilon}=800-1100 \mathrm{~s}^{-1} ; 2-T=25^{\circ} \mathrm{C}, \quad \dot{\varepsilon}=310-500 \mathrm{~s}^{-1}$; $3-T=250^{\circ} \mathrm{C}, \dot{\varepsilon}=900-1050 \mathrm{~s}^{-1} ; 4-T=250^{\circ} \mathrm{C}, \dot{\varepsilon}=280-550 \mathrm{~s}^{-1} ; \mathrm{AMg}-6: 5-$ $T=25^{\circ} \mathrm{C}, \quad \dot{\varepsilon}=1100-1300 \mathrm{~s}^{-1} ; \quad 6-T=25^{\circ} \mathrm{C}, \quad \dot{\varepsilon}=250-550 \mathrm{~s}^{-1} ; \quad 7-T=250^{\circ} \mathrm{C}$, $\dot{\varepsilon}=1200-1400 \mathrm{~s}^{-1} ; \quad 8-T=250^{\circ} \mathrm{C}, \quad \dot{\varepsilon}=190-530 \mathrm{~s}^{-1} ; \quad$ AD $-1: \quad 9-T=25^{\circ} \mathrm{C}$, $\dot{\varepsilon}=800-1200 \mathrm{~s}^{-1} ; 10-T=25^{\circ} \mathrm{C}, \dot{\varepsilon}=200-370 \mathrm{~s}^{-1} ; 11-T=250^{\circ} \mathrm{C}, \dot{\varepsilon}=920$ $1100 \mathrm{~s}^{-1} ; 12-T=250^{\circ} \mathrm{C}, \dot{\varepsilon}=330-600 \mathrm{~s}^{-1}$.

So, for alloys D-16, AMg-6, AD-1 in the considered temperature-velocity conditions of loading, we observe in this or that extent the drop of $\sigma_{-0.2}$ with temperature growth, and the increase of $\sigma_{-0.2}$ with strain rate growth. It is characteristic of many other materials and alloys [11]. The obtained data are in agreement with data of the other authors. For instance, it is mentioned for D-16 in [7] that the yield strength of the alloy is $\sigma_{+0.2}=290-300 \mathrm{MPa}$ at $T=20^{\circ} \mathrm{C}$ and $\varepsilon \dot{\varepsilon} \sim 500 \mathrm{~s}^{-1}$ (extension). In [11], for alloy 6061-T6 (that is an analog of D-16), there is $\sigma_{-0.2}=300-310 \mathrm{MPa}$ at $T=20^{\circ} \mathrm{C}$ and $\varepsilon=900 \mathrm{~s}^{-1}$ (compression) from the diagrams $\sigma-\varepsilon$. It is noted in [5] for AMg-6 that at $T=20^{\circ} \mathrm{C}$ and $\dot{\varepsilon}=270 \mathrm{~s}^{-1}$ and $2000 \mathrm{~s}^{-1}$, values of the yield strengths are $205 \mathrm{MPa}$ and $230 \mathrm{MPa}$, respectively. It is characteristic that these data confirm the velocity dependence of $\sigma_{-0.2}$ for $\mathrm{AMg}-6$ in [5]. In $[7,8]$, the authors mention that $\sigma_{+0.2}=170-175 \mathrm{MPa}$ at $T=20^{\circ} \mathrm{C}$ and $\dot{\varepsilon} \sim 500 \mathrm{~s}^{-1}$ (extension). At the same time, it is noted in $[7,8]$ that the yield strength $\sigma_{+0.2}$ is 
actually unchanged, when $\varepsilon$ is growing from static values to dynamic values (up to $10^{3} \mathrm{~s}^{-1}$ ). This difference from our data can be caused by different histories of AMg-6 deformation. Time of loading growth in sample in our experiments was $70 \mu \mathrm{s}$, and it was $\sim 5 \mu \mathrm{s}$ in $[7,8]$. However, this problem requires more comprehensive study.

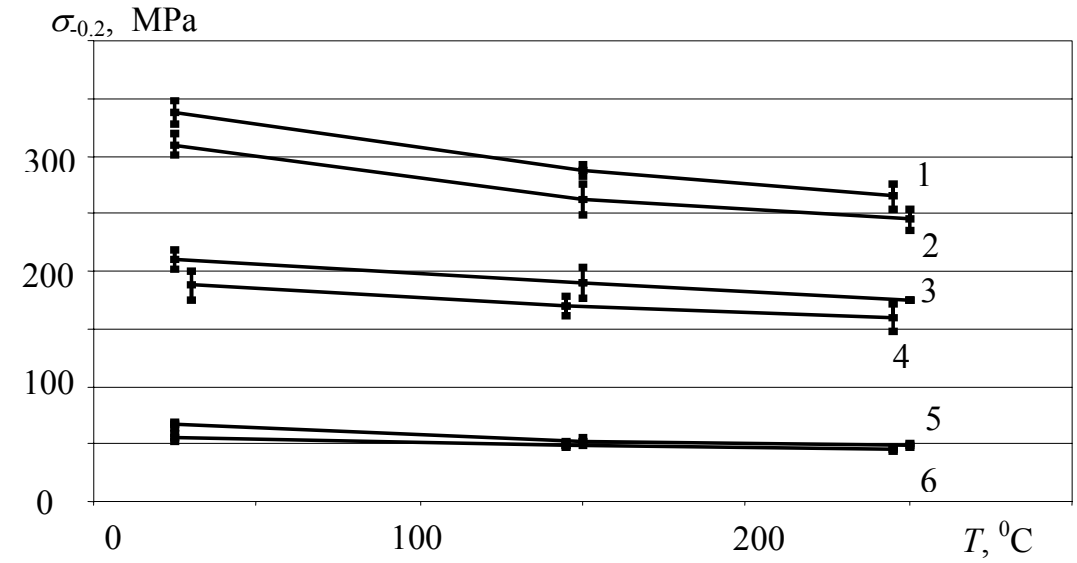

Figure 2: Temperature dependencies of $\sigma_{-0.2}$ of aluminum alloys. D-16: 1$\dot{\varepsilon}=800-1100 \mathrm{~s}^{-1} ; 2-\dot{\varepsilon}=280-550 \mathrm{~s}^{-1} ; \mathrm{AMg}-6: 3-\dot{\varepsilon}=1020-1400 \mathrm{~s}^{-1} ; 4$ $\dot{\varepsilon}=190-620 \mathrm{~s}^{-1} ; \mathrm{AD}-1: 5-\dot{\varepsilon}=800-1200 \mathrm{~s}^{-1} ; 6-\dot{\varepsilon}=200-600 \mathrm{~s}^{-1}$.

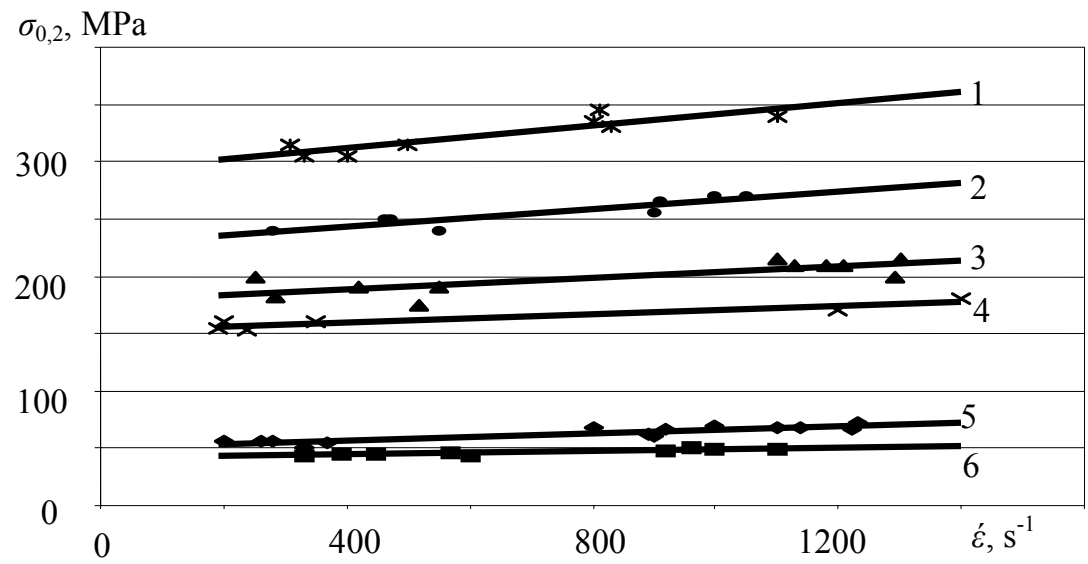

Figure 3: Velocity dependencies of $\sigma_{-0.2}$ of aluminum alloys. D-16: $1-T=25^{\circ} \mathrm{C}$; $2-T=250^{\circ} \mathrm{C} ; \mathrm{AMg}-6: 3-T=25^{\circ} \mathrm{C} ; 4-T=250^{\circ} \mathrm{C} ; \mathrm{AD}-1: 5-T=25^{\circ} \mathrm{C} ; 6-$ $T=250^{\circ} \mathrm{C}$.

No similar data have been revealed for AD-1 in Russian literature. In foreign literature, Lindholm and Yeakley [10], for alloy 1100-0 (that is an analog of 
AD-1) tested by the Kol'sky method, increase of strength properties is noted with strain rate growth.

\section{Modeling}

To create a more reliable model of behavior of aluminum alloys, additional tests were performed with dynamic extension and normal temperature. Basing on experimental results, we developed the phenomenological model of strength [13] for description of our obtained dynamic diagrams of compression and extension of aluminum alloys AMg-6, AD-1, D16 at strain rates of $10^{2}-10^{3} \mathrm{~s}^{-1}$ and temperatures of $25-250^{\circ} \mathrm{C}(298-523 \mathrm{~K})$. The model content is the following. If medium is elastic-plastic, stress intensity $\sigma_{i}$ (yield strength at uniaxial compression and extension) can be presented as function of three variables $\varepsilon_{i}^{p}$, $\dot{\varepsilon}_{i}^{p}, T$ characterizing its stress-strain state, eqn (3):

$$
\sigma_{i}=\sigma_{i}\left(\varepsilon_{i}^{p}, \dot{\varepsilon}_{i}^{p}, T\right)
$$

Here $\varepsilon_{i}^{p}$ - intensity of plastic strains, $\dot{\varepsilon}_{i}^{p}$ - intensity of rate of plastic strains, $T$ current temperature. Stress intensity $\sigma_{i}$ can be presented as product of simple functions, where each function depends only one variable:

$$
\sigma_{i}=A \cdot f_{1} \cdot\left(\varepsilon_{i}^{P}\right) \cdot f_{2}\left(\dot{\varepsilon}_{i}^{P}\right) \cdot f_{3}(T)
$$

In eqn (4), $f_{1}\left(\varepsilon_{i}^{p}\right)$ describes strain hardening, $f_{2}\left(\dot{\varepsilon}_{i}^{p}\right)$ - influence of rate of plastic strain, and $f_{3}(T)$ - thermal softening. In the expanded form, the constitutive equation of dynamic deformation is the following eqn (5):

$$
\sigma_{i}=A \cdot\left(1+a \cdot\left(\varepsilon_{i}^{p}\right)^{n}\right) \cdot\left(1+b \cdot\left(\ln \frac{\dot{\varepsilon}_{i}^{p}}{\dot{\varepsilon}_{i 0}^{p}}\right)^{m}\right) \cdot\left(1-\bar{T}^{k}\right)
$$

Here $A, a, b, m, n, k$ are constant values, which can be determined using experimental data; $\dot{\varepsilon}_{i o}^{p}=1 \cdot \mathrm{s}^{-1}-$ normalizing value of $\dot{\varepsilon}_{i}^{p}, \bar{T}^{k}=\frac{T_{r}}{T_{m}}, \mathrm{~T}_{\mathrm{m}}-$ melting temperature; $T_{\mathrm{r}}$ - current temperature.

For aluminum alloys, steel and copper tested by the SHPB method, Table 1 presents values of constant coefficients and exponents selected basing on available experimental data. The area of application of the suggested model is limited by the area of experimentally obtained characteristics. It is equal to:

$$
\varepsilon_{i}^{p} \leq 0.20 ; \quad \dot{\varepsilon}_{i}^{p} \leq 1,4 \cdot 10^{3} 1 / \mathrm{s} ; \quad T \leq T_{m}
$$


Table 1: Values of constant coefficients and exponents, eqn (5).

\begin{tabular}{|c|c|c|c|c|c|c|c|}
\hline Material & process & $A, M P a$ & $a$ & $n$ & $b$ & $m$ & $k$ \\
\hline \multirow{2}{*}{ AMg-6 } & compression & 200 & 2.45 & 0.4 & $5 \cdot 10^{-4}$ & 2.55 & 2 \\
\cline { 2 - 8 } & extension & 130 & 2.40 & 0.4 & $5 \cdot 10^{-4}$ & 2.50 & 2 \\
\hline \multirow{2}{*}{ AD-1 } & compression & 43.5 & 2.8 & 0.335 & $2 \cdot 10^{-4}$ & 3.6 & 2 \\
\cline { 2 - 8 } & extension & 30 & 2.8 & 0.330 & $2 \cdot 10^{-4}$ & 3.6 & 2 \\
\hline \multirow{2}{*}{ D-16 } & compression & 240 & 2.28 & 0.28 & $1.2 \cdot 10^{-4}$ & 3.3 & 2 \\
\cline { 2 - 8 } & extension & 220 & 2.28 & 0.28 & $1.2 \cdot 10^{-4}$ & 3.3 & 2 \\
\hline
\end{tabular}

Table 2: Experimental and calculated values of conventional yield strength at compression of aluminum alloys AD-1, AMg-6 and D-16 at various strain rates and initial temperatures of samples.

\begin{tabular}{|c|c|c|c|c|}
\hline Material & $T,{ }^{\circ} \mathrm{K}$ & $\dot{\varepsilon}, \mathrm{s}^{-1}$ & $\begin{array}{c}\sigma_{-0.2 \text { aver, }}, \mathrm{GPa} \\
\text { test }\end{array}$ & $\begin{array}{c}\sigma_{-0.2 \text { aver }}, \mathrm{GPa} \\
\text { calculation }\end{array}$ \\
\hline \multirow{6}{*}{ AMg-6 } & \multirow{2}{*}{298} & $250-550$ & $0.187 \pm 0.12$ & 0.189 \\
\hline & & $1100-1300$ & $0.210 \pm 0.08$ & 0.201 \\
\hline & \multirow{2}{*}{423} & $360-620$ & $0.169 \pm 0.09$ & 0.155 \\
\hline & & $1020-1300$ & $0.190 \pm 0.14$ & 0.169 \\
\hline & \multirow{2}{*}{523} & $190-530$ & $0.159 \pm 0.12$ & 0.170 \\
\hline & & $1200-1400$ & 0.175 & 0.177 \\
\hline \multirow{6}{*}{ AD-1 } & \multirow{2}{*}{298} & $200-370$ & $0.055 \pm 0.04$ & 0.058 \\
\hline & & $800-1200$ & $0.067 \pm 0.03$ & 0.065 \\
\hline & \multirow{2}{*}{423} & $230-290$ & $0.049 \pm 0.03$ & 0.051 \\
\hline & & $900-1200$ & $0.053 \pm 0.03$ & 0.056 \\
\hline & \multirow{2}{*}{523} & $330-600$ & $0.045 \pm 0.02$ & 0.043 \\
\hline & & $920-1100$ & $0.049 \pm 0.02$ & 0.049 \\
\hline \multirow{6}{*}{ D-16 } & \multirow{2}{*}{298} & $310-500$ & $0.310 \pm 0.09$ & 0.320 \\
\hline & & $800-1100$ & $0.338 \pm 0.1$ & 0.340 \\
\hline & \multirow{2}{*}{423} & $280-520$ & $0.263 \pm 0.14$ & 0.280 \\
\hline & & $800-1100$ & $0.288 \pm 0.045$ & 0.300 \\
\hline & \multirow{2}{*}{523} & $280-550$ & $0.245 \pm 0.09$ & 0.245 \\
\hline & & $900-1050$ & $0.265 \pm 0.11$ & 0.263 \\
\hline
\end{tabular}

Tables 2 and 3 present values of conventional yield strength at compression $\left(\sigma_{-0.2}\right)$ and extension $\left(\sigma_{+0.2}\right)$, which are experimental and calculated by $(5)$ for aluminum alloys AD-1, AMg-6 and D-16 at various strain rates and initial temperature of samples. And for example, Fig 4 shows $\sigma-\varepsilon$ diagrams of AMg-6 compression and extension, which are experimental and calculated by eqn (5).

One can see in Table 2, Table 3, and Fig 4 that the suggested elastic-plastic model is in satisfactory agreement with the experimental data within test error. 
Table 3: Experimental and calculated values of conventional yield strength at extension of aluminum alloys AD-1, AMg-6 and D-16 at various strain rates and normal temperature of samples.

\begin{tabular}{|c|c|c|c|c|}
\hline \multirow{2}{*}{ Material } & \multirow{2}{*}{${ }^{\circ}{ }^{\circ} \mathrm{K}$} & $\dot{\varepsilon}, \mathrm{s}^{-1}$ & $\begin{array}{c}\sigma_{+0.2 \text { aver, }}, \mathrm{GPa} \\
\text { test }\end{array}$ & $\begin{array}{c}\sigma_{+0.2 \text { aver, }} \mathrm{GPa} \\
\text { calculation }\end{array}$ \\
\hline \multirow{2}{*}{$\mathrm{AMg}-6$} & \multirow{2}{*}{298} & $640-800$ & $0.141 \pm 0.05$ & 0.147 \\
\cline { 3 - 5 } & \multirow{2}{*}{298} & $1200-1450$ & $0.156 \pm 0.08$ & 0.152 \\
\cline { 3 - 5 } & & $210-370$ & $0.040 \pm 0.08$ & 0.040 \\
\hline \multirow{2}{*}{$\mathrm{DD}-1$} & \multirow{2}{*}{298} & $230-1100$ & $0.043 \pm 0.08$ & 0.045 \\
\cline { 3 - 5 } & & $650-1130$ & $0.285 \pm 0.05$ & 0.288 \\
\hline
\end{tabular}

\section{Conclusion}

Studies of dynamic diagrams of uniaxial compression of alloys AMg-6, AD-1, D-16 were performed at strain rates $\dot{\varepsilon}=200-1400 \mathrm{~s}^{-1}$ and temperatures $T=25-$ $250^{\circ} \mathrm{C}$. Temperature and velocity dependencies of yield strengths $\sigma_{-0.2}$ were obtained. Among the tested alloys, D-16 has the highest strength. The strongest change of $\sigma_{-0.2}$ with growth of $T$ and $\dot{\varepsilon}$ is revealed for D-16, and the weakest - for AD-1. Additional tests were performed with dynamic extension and normal temperature.

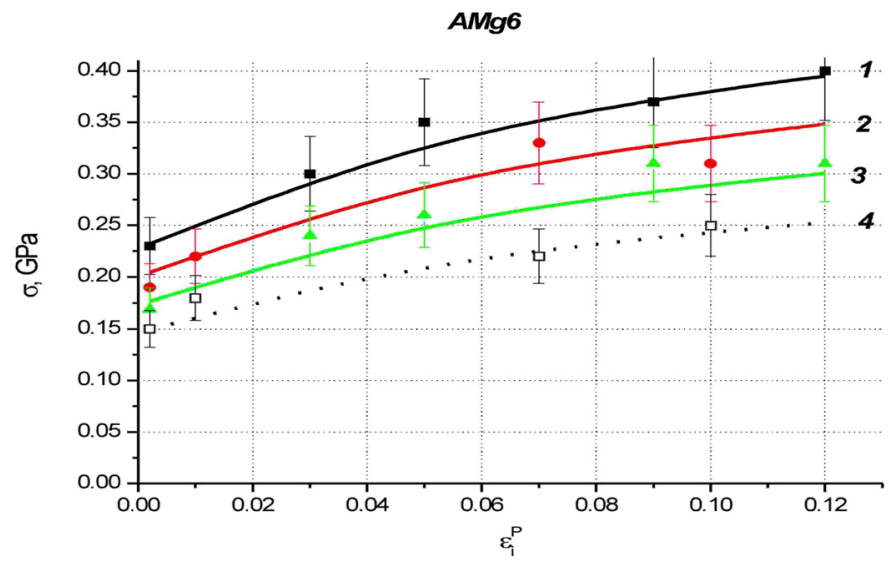

Figure 4: Experimental (different form points) and calculated (solid and dotted lines) $\sigma-\varepsilon$ diagram of compression and extension of aluminum alloy AMg-6 at strain rate of $10^{3} \mathrm{~s}^{-1} .1-T_{0}=298^{\circ} \mathrm{K}$ (compression), 2$T_{0}=423^{\circ} \mathrm{K}$ (compression), $3-T_{0}=523^{\circ} \mathrm{K}$ (compression), $4-T_{0}=298^{\circ} \mathrm{K}$ (extension). 
Basing on experimental results, we developed the phenomenological model of strength for description of our obtained dynamic diagrams of compression and extension of aluminum alloys. The presented results can be helpful for conduction of various strength calculations, as well as for prediction of material behavior under dynamic loading [13].

\section{References}

[1] Kol'sky H., An Investigation of the Mechanical Properties of Materials at Very High Rates of Loading. Proceedings of the Physical Society, Section $B$, 62, pp. 676-700, 1949.

[2] Muzychenko V.P., Kashenko S.I. and Guskov V.A., On application of split Hopkinson bar method. Plant laboratory (Rus.) 1, pp. 58-66, 1986.

[3] Novikov S.A., Pushkov V.A., Sinitsyn V.A. and Tsoi P.A., Study of the Baushinger's effect at dynamic loading. Appl. Mech. and Tech. Phys. (Rus.), 4, pp. 163-169, 1995.

[4] Shalin R.E. Aviation materials. Reference book, v.4, part 1, ONTI-VIAM, Moscow, pp. 180-185, 1982.

[5] Bol'shakov A.P., Novikov S.A. and Sinitsyn V.A., Study of the tension and compression uniaxial dynamic diagrams of copper and alloy AMg6. Problems of strength (Rus.), 10, pp. 87-88, 1979.

[6] Glouschenkov V., Novobratsky R. and Bourmistrov A., Influence of the spread in values of aluminum alloy dynamic properties upon the final results of magnetic-pulse strain, Proc. of the DYMAT-91, Physics Eds., Association DYMAT: Strasbourg, pp. C3/331-C3/334, 1991.

[7] Stepanov G.V., Astanin V.V. and Romanenko V.I., Study of properties of the aluminum alloys at dynamic loading. Problems of strength (Rus.), 2, pp. 59-63, 1983.

[8] Popov N.N., Ivanov A.G., Strekin V.P. and Barinov V.M., Study of AMg6 dynamical behaviour. Problems of strength (Rus.), 12, pp. 50-54, 1981.

[9] Higashi K., Mukai T. and Kaizu K., The microstructural evolution during deformation under several strain rates in a commercial 5182 aluminum alloy, Proc. of the DYMAT-91, Physics Eds., Association DYMAT: Strasbourg, pp. C3/347-C3/352, 1991.

[10] Lindholm U.S., Yeakley L.M., High strain rate testing: tension and compression. Experimental Mechanics, 8(1), pp. 1-9, 1968.

[11] Mayden S., Green S., Compressive strain-rate tests on six selected materials at strain rate from 10-3 to104 in/in/sec. Applied Mechanics, Ser. E, v. 33(3), pp. 20-30, 1966.

[12] Novikov S.A., Pushkov V.A., Dynamic crack-resistance of B4C-based materials, Proc. of the Conf. on Urgent Problems of Protection and Safety, Publ. House of SIC "Spetsmaterials": St. Petersburg, pp. 4-8, 1999.

[13] Glushak B.L., Ignatova O.N., On modeling of dynamic deformation diagrams. Questions of Atomic Science and Technique (Rus.), 2, pp. $45-49,1998$. 